\title{
Intelligent Information Bypass for More Efficient Emergency Management
}

\author{
Z. Vetulani ${ }^{1}$, J. Osiński $^{2}$ \\ ${ }^{1}$ Adam Mickiewicz University in Poznań, Poland \\ E-mail: vetulani@amu.edu.pl \\ ${ }^{2}$ Quality Assurance Department, Cognifide Polska, Poland
}

Received: 17 March 2017; revised: 18 June 2017; accepted: 20 June 2017; published online: 30 June 2017

\begin{abstract}
An information bottleneck is one of the typical failure causes in emergency situations. In this paper we focus on a novel approach that consists in applying an intelligent bypass involving natural language processing and AI technologies to minimize the negative effects of the information bottleneck. The system prototype has been implemented for a public security context (anti-hooligan prevention in large scale sport events). It may be adapted to other emergency situations (from anti-terrorist operations to natural disasters). The added value over the standard function of a bypass is the AI-based processing of the information entered to the bypass. As an example of reasoning performed by the bypass we discuss time-and-space information processing implemented in the beta-prototype of the POLINT-112-SMS system. We present the architecture of this system and provide examples of natural language dialogues between human system users and the system (registered at system testing). We discuss a number of possible application areas for the information bypass technology.

Key words: emergency management, information bottleneck, decision support, natural language processing, spatial reasoning.
\end{abstract}

\section{INTRODUCTION}

The research presented in this paper was directly inspired by observations of various undesirable events demanding quick and efficient intervention in order to limit potential or actual damage in which the effectiveness depends on realtime acquisition and (online) processing of essential information. We discuss results obtained under a Polish Government grant within the Polish Platform for Homeland Security ${ }^{1}$.

We are particularly interested in unusual and atypical situations, highly damaging if not countered, and where the time factor is of great importance. Classical examples include situations of threat for health or life because of high risk of an uncontrolled and aggressive crowd, terrorist attacks and the resulting panic, natural or technological disasters, as well as many other causes. Well-organized modern societies are equipped with services, systems and procedures to act properly in the critical situations and prevent them when possible. However, in numerous situations reported by the media, one may see that the traditional instruments do not always solve the problem completely, and sometimes completely fail. A frequent case is the information bottleneck ${ }^{2}$ resulting with low quality of the transferred information and sometimes with the lack of any information at all.

\footnotetext{
${ }^{1}$ Selection of the main results of the grant was published (in Polish) in an extensive report ( [1]). See also ( [2]).

${ }^{2}$ A computer scientist may be tempted to consider the phenomenon of information bottleneck as a kind of the concept of network bottleneck (e.g. the internet bottleneck). However, not all methods applicable to the internet bottleneck appear correct in case of the information bottleneck. For example, methods inspired by network management solutions consisting in restrictions imposed on certain sets of users (information providers) (cf. Comcast Corp. "Understand congestion management on our network"), when applied in the context of crisis management, may result in fatal decisions.
} 
A significant example of the inefficiency of traditional solutions applied by one of the most developed countries was the measures taken at the event on July 22, 2011, in Norway $^{3}$ where two terrorist attacks were committed by Anders Breivik. Just after having bombed the Norwegian Prime Minister's buildings in Oslo and killed eight people there, he attacked and killed 69 people on the Utrya Island. The Norwegian and international media widely commented on the government commission report (Norway government report ( [3]), which was also disseminated within NATO ( [4]) showing obvious errors of the public security services responsible for critical information processing (cf. ( [5]), $([6])^{4},([7])^{5}$ ). In particular, the police had a detailed description of the terrorist, including the number plate of the car he used to drive to the island, but did not make use of this information. Part of the crucial information arrived too late to stop the mass slaughter (although it had been available earlier). This case has several features typical of our situations of interest:

- the information flow was rich in partial data arriving from various places at various moments,

- the amount of information was too abundant with respect to the processing efficiency of the involved services,

- effectiveness of security measures depended on the possibility of on-line information processing.

To face the identified needs we have designed, implemented and tested a system prototype whose role is to serve as a tool for the security forces. As main priorities we consider:

- avoiding information bottlenecks and other causes of low quality of information arriving to the decision center,

- providing on-line integration of partial and scattered pieces of information into a coherent image of the situation.

The event reported above is by no means an isolated case. From time to time the public opinion is shocked by large scale incidents as the one in Ferguson, Missouri (USA), where on August 9, 2014, a white police officer fatally shot an 18-yearold African-American male. The consequence of the event was a series of protests and civil disorder. As a response the state of emergency was declared. The information necessary for efficient reactions of public services was missing or incomplete. Some new important facts were often identified too late (after careful analysis of the complete communication recordings, including the description of events preceding the critical moment). If the information had been processed earlier, the consequences could have been less dramatic. (In Annex 1 the reader will find fragments of the recorded messages that failed to be processed in the appropriate time.)

Our theoretical investigations have been validated for the carefully selected study case that we have considered as representative for many aspects that we find essential.

\section{BENCHMARKING CASE - EARLY PREVENTION IN HIGH RISK MASS EVENTS (SOCCER MATCHES)}

According to a common definition emergency is a situation that poses an immediate risk to health, life, property, or environment. By emergency management we mean measures taken in order to prevent the harmful effects of emergencies. Where applicable, prevention is considered as one of the crucial instruments of emergency management (see Wikipedia articles "Emergency" and "Emergency management" (last accessed on June 14, 2017). As a benchmarking case we have chosen early prevention in situations where human life or health is threatened by an aggressive and hostile crowd. Such situations occur frequently at mass sport events of large size (e.g. 20,000 soccer fans at a stadium). In such situations early prevention is of particular importance. Information management is crucial to identify threats at the earliest possible stage to provide correct diagnosis and draw useful conclusions for the decision maker (decision support). The classical organization involves monitoring devices (stationary or mobile cameras), human observers (agents) connected to the information processing center (or sometimes directly to the decision center) and various kinds of hot-lines connected to the emergency staff.

Both hardware-based monitoring and observers deployed out in the field require human analysts to interpret both camera recordings and incoming messages. This solution is biased by risks similar to those that materialized in the situations described above in the Introduction (information bottlenecks and resulting informational and operational inefficiency).

To limit the possible after-effects of these kinds of risk we propose a solution consisting in the application of an intelligent information bypass.

\section{INTELLIGENT INFORMATION BYPASS AND ITS IMPLEMENTATION}

\section{1. A novel approach: intelligent information bypass with language competence}

Fig. 1 illustrates the idea of an intelligent information bypass implemented as a set of NLP tools including mod-

\footnotetext{
${ }^{3}$ By that date the prototype of the POLINT-112-SMS system (described in this paper) was already implemented.

${ }^{4}$ Reuters: "Once the bombing took place, a witness's description of Breivik, which was phoned in to the police, was not passed on to officers in the field for 20 minutes."

${ }^{5}$ Guardian: "Despite receiving a detailed description of (...) Breivik 10 minutes after he detonated a car bomb in the centre of Oslo, a catastrophic breakdown in police communications meant the rightwing terrorist was able to make the two-hour car journey to Utřya Island, passing two police cars (...) the communications blunder - resulting in a note containing the description of Breivik being left on a table in the police operations room - was one of a series of failures which added to the death toll."
} 


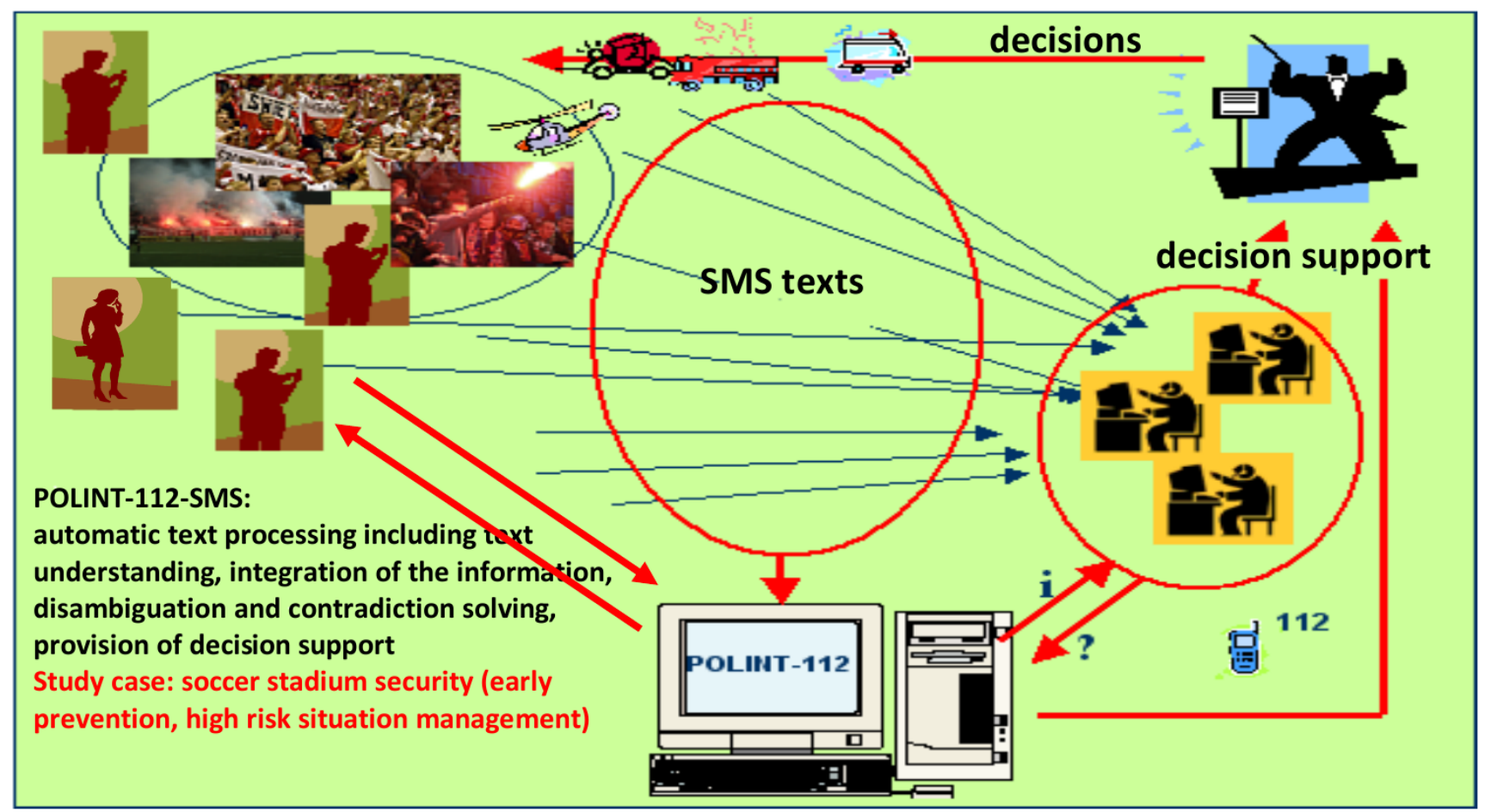

Fig. 1. Intelligent information bypass - example of application. Blue arrows refer to the traditional communication channel(s), red arrows from and to the server represent the channel used by the bypass

els, algorithms and heuristics. The meaning we give to the term 'bypass' is derived from traditional meanings in cardiac surgery ${ }^{6}$ or telecommunications. What is novel in the concept of intelligent bypass with respect to the traditional meaning of the term bypass is its extension by information processing functions and natural language competence (as far as we know, none of the presently used police support systems is equipped with the comparable functionalities).

Application of the bypass (see red arrows at Fig. 1) consists in creating an additional communication channel to double or sometimes even replace the existing one (blue arrows) and to perform additionally some important analytic functions. This communication channel essentially explores the natural language channel involving natural language understanding and is equipped with dialogue capacities. The language competence of the systems discussed in this paper makes it possible to implement the bypass functionality in the high level, user-friendly way where no special communication training is required from the users (information providers, analysts).

The processing involves:

- integrating the pieces of partial information that originate from various sources but concern one given aspect or person,
- evaluating the credibility of the information sources and verifying their content; in particular, resolving information conflicts (contradictory information).

Besides its basic function of reducing the effects of the information jam, an intelligent bypass is supposed to perform the initial information processing (including authentication). The processing should be done in interaction with both senders and addressees, using build-in knowledge and reasoning mechanisms where appropriate.

As the case study we developed the Polint-112-SMS sys$\mathrm{tem}^{7}$. It was designed and implemented as an intelligent bypass for the class of situations similar to those represented in Fig. 1. The complete architecture and functionalities of Polint112-SMS are presented in the following section, whereas the language resources used in the system implementation in Annex 2.

\section{2. Polint-112-SMS functionalities and architecture}

The main feature of the system is its capacity to be supplied with information directly by a human agent in natural language and to interact with him in a mode that mimics the natural human-to-human dialogues which does not require any special training of agents. Here are some characteristic

\footnotetext{
${ }^{6} \mathrm{Cf}$. ( [8]) for the first successful coronary bypass

7 The name refers to the public telephone alert system for critical situations in common use in Europe (112 emergency telephone number) and to the SMS technology
} 
features of the dialogue competence proper to POLINT-112SMS.

- The dialogue between the system and an agent (via SMS or any private instant messaging system) is autonomous, i.e. it does not involve a human operator. It is performed in natural language. Due to the deep dialogue understanding faculty, the system is able to collect consistent information about situations, events, and individuals.

- The system may initiate a dialogue with various users (agents, investigators, third persons) in order to acquire additional, critical or simply useful information about events or individuals already identified.

- The system user (investigator, analyst) may request gathering and storing information about individuals or events, including those still not identified by the system.

- The system is able to autonomously identify threats on the basis of the incoming information.

- It is also able to answer user questions about the current state of knowledge.

- It may process an important number of dialogue sessions in parallel and autonomously, i.e. without involving a human operator.

- It is able to monitor ("spy on") the traditional dialogue between agents and the (human) operator receiving messages. The purpose is to assist the operator in the processing of information through:

- automatic information gathering (collecting facts),

- providing the operator with procedures and instructions appropriate to the given (current) situation (on the basis of the system's knowledge),

- suggesting questions /information requests/ the operator should address to users if necessary in order to complete knowledge gaps.

Let us remark that implementing the above functionalities within a system with a vocal input/output fully covers the requirements of the traditional telephone service "112" without some of its intrinsic weak points, however.

The following 1) to 6) are the main modules providing the system with the functionality of an "intelligent bypass".

1) The Natural Language Processing Module (NLPM) is composed of the Text Understanding Module for message text analysis (lexical, syntactic and semantic), and the Text Generation Module for generating text messages addressed to the users (informers, analysts, third persons).

2) The Dialogue Maintenance Module (DMM) is responsible for deep understanding and dialogue with the user. Its role is to select the best possible interpretations of a sentence supplied by the NLP module. It takes into account the system's knowledge base and the history of the dialogue. It may ask questions in order to fill up gaps (to feed the Situation Analysis Module). The DMM is also responsible for matching queries and (often incomplete) answers, performing anaphora analysis and disambiguation. The DMM communicates directly with the NLP and SAM modules.

3) The Situation Analysis Module (SAM) is the brain of the system. It provides the main analytical functions of the intelligent bypass, it reasons about the structures without communicating directly with the informers in order to form a complete representation of the situation on the basis of incoming facts and the general knowledge of the world. It is composed of the following submodules:

a) The Knowledge Unification Module (KUM). Its role is to merge partial descriptions provided by different agents and supply a coherent piece of knowledge compatible with the general system's knowledge. The module is supposed to identify and solve all kinds of contradictions that may have been entered to the system.

b) The Reasoning Module (RM) performs reasoning based on the knowledge unified and merged with the world knowledge of the system (knowledge particular to the critical situation, static knowledge of the world, conceptualization, rules, etc.). In some cases it may change the categorization of events or individuals (e.g. changing "entry" into "intrusion"), it may cancel some unimportant events, decide about location, etc.

c) The Internal Information Retrieval Module (IIRM) is responsible for retrieving information requested by the user from the system's knowledge. The module is either activated on the user's request or automatically once the answer has been computed by the system.

4) The Time-Space Processing Module (TSPM) stores and processes the knowledge about special and temporal relations involving individuals, events and situations as arguments. As a support for the reasoning competence of the system, these relations are crucial for the security management in critical, dynamically evolving situations. The functionalities of TSPM are the following:

- adding or removing spatio-temporal relations between objects (the consistency checking algorithm runs in background),

- translating the language relations into the inside module structures,

- interpreting the module structures as language relations that can be used by DMM and SAM,

- calculating the relation between two given objects (if the relation was not directly inserted to the system, the advanced composition algorithms ran),

- comparing two relations to check whether they can (or cannot) be used to describe the same objects,

- finding localization of a given object (advanced heuristics were implemented to find the answer that best fulfils the user requirements),

- loading the full map of the analysed area from an XML file,

- removing all relations or a set of relations that suit a 
specific template.

The TSPM functions are executed from the SAM module by running its specific procedures.

5) The Wordnet type ontology ("PolNet-Polish Wordnet") contains information about the world concepts contained first of all in the basic relations of hyponymy/hyperonymy as well as other relations supporting reasoning ( [9])).

6) The World Knowledge Module (WKM) stores permanent knowledge about the world (maps of the stadium sectors, maps of the surrounding area, procedural knowledge le.g. standard procedures of critical situations management/, stereotypical knowledge about events and human behavior).

Besides the above main modules, the complete architecture includes:

7) Three knowledge bases connected to the SAM module which contain information provided by system users (or by the other system modules) about events, situations and notifications, including the Notifications Knowledge Base, Events Knowledge Base, and Situation Knowledge Base. Each event is associated with one or many notifications. Also, each situation is connected with one or many events.

8) The SMS Gate. This module provides the functionality that allows two-direction SMS (short message service) communication between the system and an informer in order to support the dialog maintenance controlled by the system itself. There are two separate sub-modules responsible for sending and receiving messages, respectively.

9) The Crisis Management Center Panel. This module provides access to information collected in the system knowledge base and allows to create information requests (in natural language sentences) by an operator.

Fig. 2 presents the POLINT-112-SMS system architecture showing all main modules and the dependencies between them.

\section{3. Empirical approach to system design and validation Some of these results contributed in an essential way to the $\mathrm{PhD}$ dissertations of $\mathrm{M}$. Kubis ( [10]), J. Osiński ( [11]) and J. Walkowska ( [12])}

The implementation of the architecture presented above was based on robust language resources and algorithmic tools, some of them existing before the start of the project (e.g. general text corpora, dictionaries, grammars), while others (such as the lexical ontology PolNet and domain- or applicationspecific corpora /dialogues, SMS/) were obtained/adapted within or in parallel to its development ( [13]) (cf. Annex 2). Both language coverage and reasoning competence depend on the completeness and adequacy of the project engineering resources. Dictionaries, grammars, conceptualization and elements of general knowledge of the world must be taken into consideration in order to implement reasoning. Decisions concerning the size and content of these resources were taken on the basis of:

- direct observations of the human behavior in humanto-human communication ${ }^{8}$ or in "wizard-of-Oz" experiments,

- observation of the human-system interaction at various stages of system development and testing, but also

- common sense knowledge about the world and language.

The Wizard of Oz experiments involve experiment participants who are convinced that they interact with a computer which has a human-like communication competence, whereas in reality human participants get into interaction with a human via a computer. Such experiments were first run in the laboratory of Alphonse Chapanis at John Hopkins University in the 1970s. The term "Wizard of Oz experiment" was introduced by J.F. Kelley ( [14]). In our case, the Wizard of Oz techniques contribute both to the system development (as an experimental basis to build/improve the user model) and to partial evaluation at various stages of the system development. In particular, the crucial system modules, i.e. NLPM, DMM, SAM and TSPM, were the main addressees of this "Wizardof-Oz"-based evaluation methodology. For the utility of the Wizard of Oz methodology in the design and evaluation of human-machine systems cf. e.g. [15].

An adequate specification of the system's language competence was required to describe and supply the respective language engineering resources: dictionaries, formal grammar rules, rules of inference for the reasoning engine, and ontology concepts for knowledge representation. To define the set of resources in order to run the initial version(s) of the system we decided to create a corpus of typical messages (questions, answers, comments, etc.) specific to the chosen application domain. ${ }^{9}$ The initial corpus of 1364 sentences was obtained in five experiments in the convention of using a Role Playing Game (RPG) ${ }^{10}$ and involving a Wizard of $\mathrm{Oz}$ as one of the game actors. These experiments were performed with participation of project experts assuming roles of the game actors. The participation of Police experts with practical operational experience of the field was decided to ensure adequacy and completeness for the language model (vocabulary, syntax, communication conventions) used to implement the language competence. Besides the acquisition of domain specific vocabulary, the experiments permitted identification of the most important syntactic structures and discourse phenomena (like anaphora), and the categorization of the most frequent typing errors, as well as the introduction of specific ontological concepts in order to best implement the time-space phenomena.

The method of evaluation of the system results directly

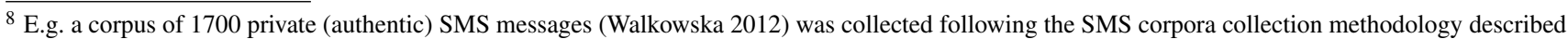

${ }^{9}$ The necessity of redefining the language model will be a natural cost of readapting the Polint-112-SMS system to other application domains

${ }^{10}$ The idea of using the RPG as an experiment platform has been explored for acquiring specific knowledge in engineering tasks of various kinds (cf. applications for water engineering ( [16]))
} 


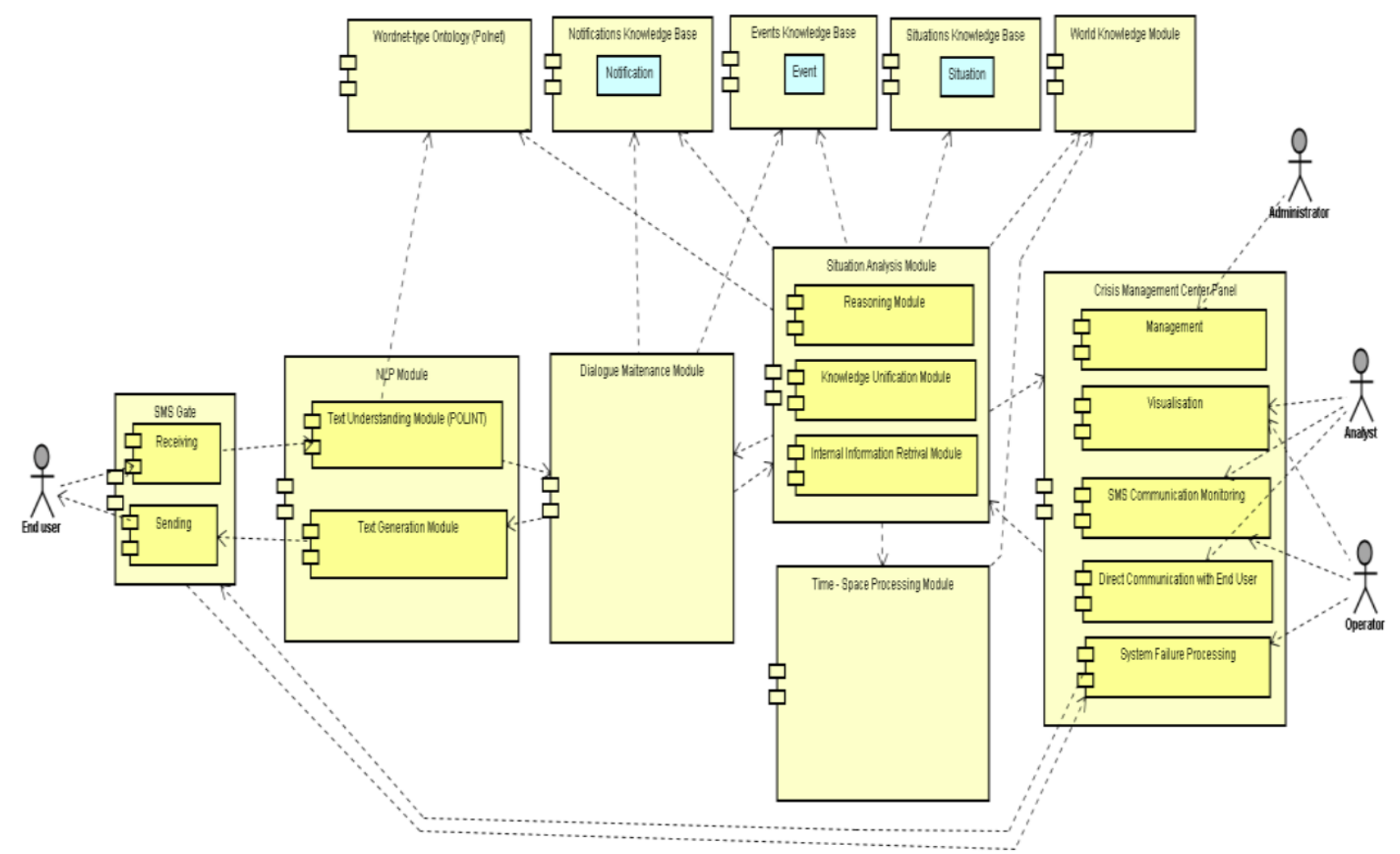

Fig. 2. POLINT-112-SMS architecture

from the project development model described in ( [17]). The system was tested during successive iteration loops. Within the first iteration loop we obtained the first version of the prototype with some main functionalities already working. Evaluation at each development cycle consists in observations of the system behavior, then corrections, modifications and extensions. After a number of cycles, the evaluation becomes a "beta" testing. It means that the evaluation is performed by testers including end users and in conditions close to realworld situations. The "opportunity" for testing in real highrisk and/or critical situations is, however, rare and undesirable in the systems designed for prevention purposes in extremely dangerous situations that we hope will never occur in the real world. Instead, the beta testing is performed in experimental settings or in the real situations (here a real soccer match), where we still should not expect many situations of interest for the system designers. Therefore, in the early cycles of testing it is particularly desirable to involve a Wizard of $\mathrm{Oz}$ as an element of the tested architecture in order to avoid (at least minimize) frequent interruptions of the system due to the bugs and gaps in the system resources (cf. also (Vetulani et al. 2010)).

The applied iterative development and evaluation model appeared efficient: the language competence (cf. Annex 3 for samples of system-user dialogues) of the final system was strong enough to deal with dialogues at the complexity level of interactions recorded in Ferguson on August 9, 2014 ( [18]). (Cf. Annex 1).

\section{4. The function of the intelligent bypass in the time-space information processing in the POLINT-112-SMS system}

The key elements of the system include those responsible for gathering and processing time-space relations between persons, locations, objects, events, and situations observed in some well-defined spatiotemporal area which is a product of some 3D area (here a football stadium and its close surroundings) and a time interval (here from the opening of the stadium for the public until the last fan leaves the stadium). The management of spatiotemporal relations is a mandatory element of all applications that involve a description of a dynamically evolving environment and are supposed to support a human in the decision process referring to this environment (e.g. expert systems). This functionality serves the basic human competence acquired through evolution: the ability to 
act efficiently in a natural, dynamic environment (space) is fundamental for the survival of humans as a species; efficient processing of temporal relations is crucial for cause-effect reasoning and decision taking.

Concerning time and space processing, the intelligent information bypass accesses information coming from various sources: external systems (e.g. analysis of traditional camerabased monitoring), but also human informers (as e.g. trained service staff) or accidental (untrained) users that may report important, unexpected aspects.

It is important to bear in mind that each person involved may supply information that is a) incomplete (limited access to the information source), b) inaccurate (because of lack or insufficiency of observation tools, bad visibility), or c) subjective (biased by individual perception, experience, etc.). The quality of the observations may be impacted by the dynamism of situation changes, fuzziness of the observed elements, or natural visibility limitations. All these factors result in particular natural language messages usually lacking precision and are qualitative rather than quantitative. ${ }^{11}$

As a final result, a content-independent reasoning module was created and later integrated with the POLINT-112-SMS architecture $^{12}$.

The possible lack of precision of individual observations (made by one observer) may often be compensated by complementary observations by other independent observers, as illustrated in Figures $3 \mathrm{a}$ and $3 \mathrm{~b}$. Although the informative content of a single qualitative message (e.g. object $A$ is situated to the west of $B$, see Figure $3 a$ ) is limited and imprecise, its fusion with other, also imprecise relations ( $A$ is situated to the south of $C, A$ is situated to the north of $D, A$ is far to $E$ and close to $F$, see Figure $3 \mathrm{~b}$ ) will produce surprisingly good effects (quite precise localization). The reasoning is based on a simple composition of relations.

In order to process correctly spatio-temporal information in the POLINT-112-SMS a formalism for the qualitative relation description has been introduced: the eXtended Cardinal Directions Calculus (XCDC) model which is a threedimensional extension of the classic direction-relation Cardinal Direction Calculus (CDC) model ( [19]), allows collecting and storing spatiotemporal data, as well as performing calculations on spatial and temporal relations involving people, objects, events or locations (cf. [20]). The key idea of the standard CDC formalism is based on dividing the plane around the reference object (i.e. the object from which the direction relation is determined) into nine regions named after the geographical directions: NW, N, NE, W, O (central region meaning the same location), E, SW, S and SE. These areas, called direction tiles, are closed, unbounded (except for $\mathrm{O}$ ), their interiors are pairwise disjointed and their union is the whole plane. Directions between the reference object $A$ and target object $B$ are represented in a $3 \times 3$ matrix denoted by $\operatorname{dir}(\mathrm{A}, \mathrm{B})$ is defined as follows:

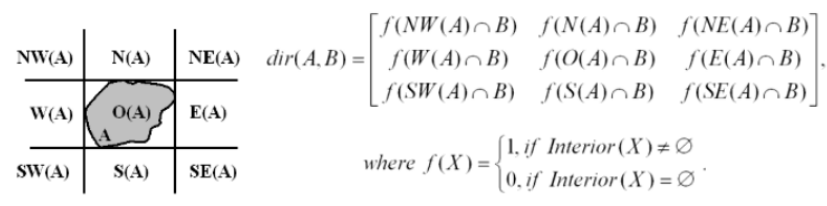

However, in the XCDC formalism we consider an object as a combination of both a temporal span (a time interval, one dimension) and a spatial extension (space region) expressed in two dimensions (as we make abstraction from the actual vertical dimension of these objects). To distinguish between geographic direction and the element of a matrix, we add the symbol * to the former (i.e. $N^{*}$ denotes the geographic

\footnotetext{
${ }^{11}$ These observations were confirmed in simulation experiments

${ }^{12}$ It may be explored as a stand-alone module in various applications
}

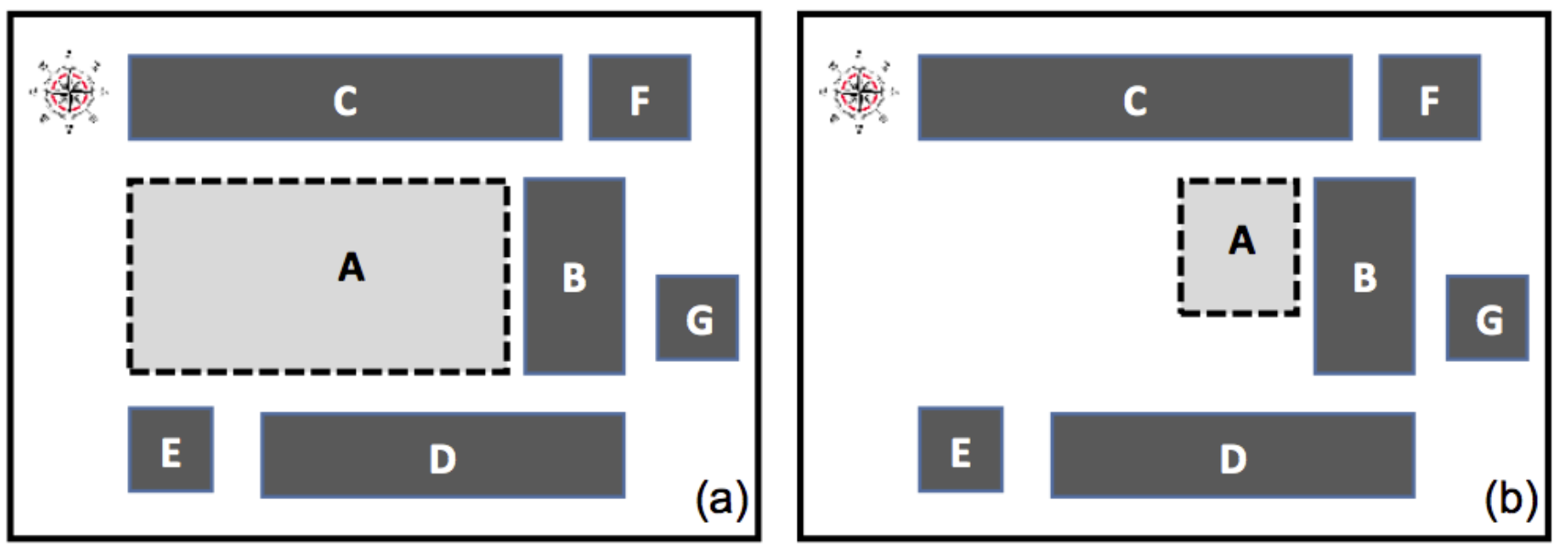

Fig. 3. Picture (a) shows the possible location of A (dotted rectangle) on the ground of a simple qualitative relation (the object $A$ is to the west of $B$ ), whereas (b) is elaborated on the basis of five qualitative relations (the object $A$ is to the west of $B, A$ is to the south of $C$, $A$ is to the north of $D, A$ is close to $F$ and $A$ is far from $E$ 
Tab. 1. Characteristics for 3 experiments. XCDC-\% presents the percentage of messages with time-space information representable in the XCDC model using the relations defined; SYS-\% presents the percentage of correctly parsed and interpreted messages

\begin{tabular}{c|c|c|c|c|c|c}
\hline Stadium & Date & ParticipatingAgents (nb) & Nb of SMS & Nb of S-TEvents & XCDC-\% & SYS-\% \\
\hline FC Warta & $2009-09-12$ & 9 & 297 & 210 & $94.8 \%$ & $82.9 \%$ \\
\hline FC Warta & $2010-02-17$ & 12 & 232 & 151 & $92.7 \%$ & $73.5 \%$ \\
\hline FC Olimpia & $2010-06-23$ & 7 & 457 & 152 & $91.4 \%$ & $61.5 \%$ \\
\hline
\end{tabular}

north direction, while $N$ describes a direction-relation matrix). With a $3 \mathrm{D}$ representation we can describe situations using three main projections: on the $N^{*}-E^{*}$ plane, on the $T-N^{*}$ plane and on the $T-E^{*}$ plane. Finally, we define the relation between two spatio-temporal objects $A$ and $B$ as follows:

$$
\begin{aligned}
T S(A, B)= & {\left[\operatorname{dir}_{N^{*}-E^{*}}(A, B), \operatorname{dir}_{N^{*}-E^{*}}(B, A),\right.} \\
& \operatorname{dir}_{T-N^{*}}(A, B), \operatorname{dir}_{T-E^{*}}(B, A), \\
& \left.\operatorname{dir}_{T-E^{*}}(A, B), \operatorname{dir}_{T-E^{*}}(B, A)\right],
\end{aligned}
$$

where $\operatorname{dir}_{X-Y}(A, B)$ denotes a direction-relation matrix for the projection on the $\mathrm{X}-\mathrm{Y}$ plane.

The ontology of spatio-temporal relation was developed ( $[21,22])$ (see Fig. 4 below) and became a tool useful for classifying spatio-temporal relations and easing their precise identification in the user-system communication. We attribute symbolic names to the relations and divide them into the categories which describe their relationship with the reference object (internal/external).
All messages that arrive to the system (e.g. from information provider) are analyzed in order to fix the spatio-temporal information they contain (or refer to). Any identified binary relation is then added to the knowledge base as a quintuple which contains:

- the unique identifier of the first argument (e.g. ID of a person),

- the unique identifier of the second argument (e.g. an event like a fight in a group of fans),

- the spatio-temporal relation described in conformance with the XCDC model (in the form of six binary $3 \times 3$ direction-relation matrices; e.g. representing the relation that might be described in natural language as follows: to be to the north of the location of the event after termination of this event),

- qualitative spatial distance relation (e.g. near),

- qualitative temporal distance relation (e.g. soon after).

In order to test correctness of the selection of the set of semantic primitives for the time-space event representation, three experiments in the real environment (soccer stadium)

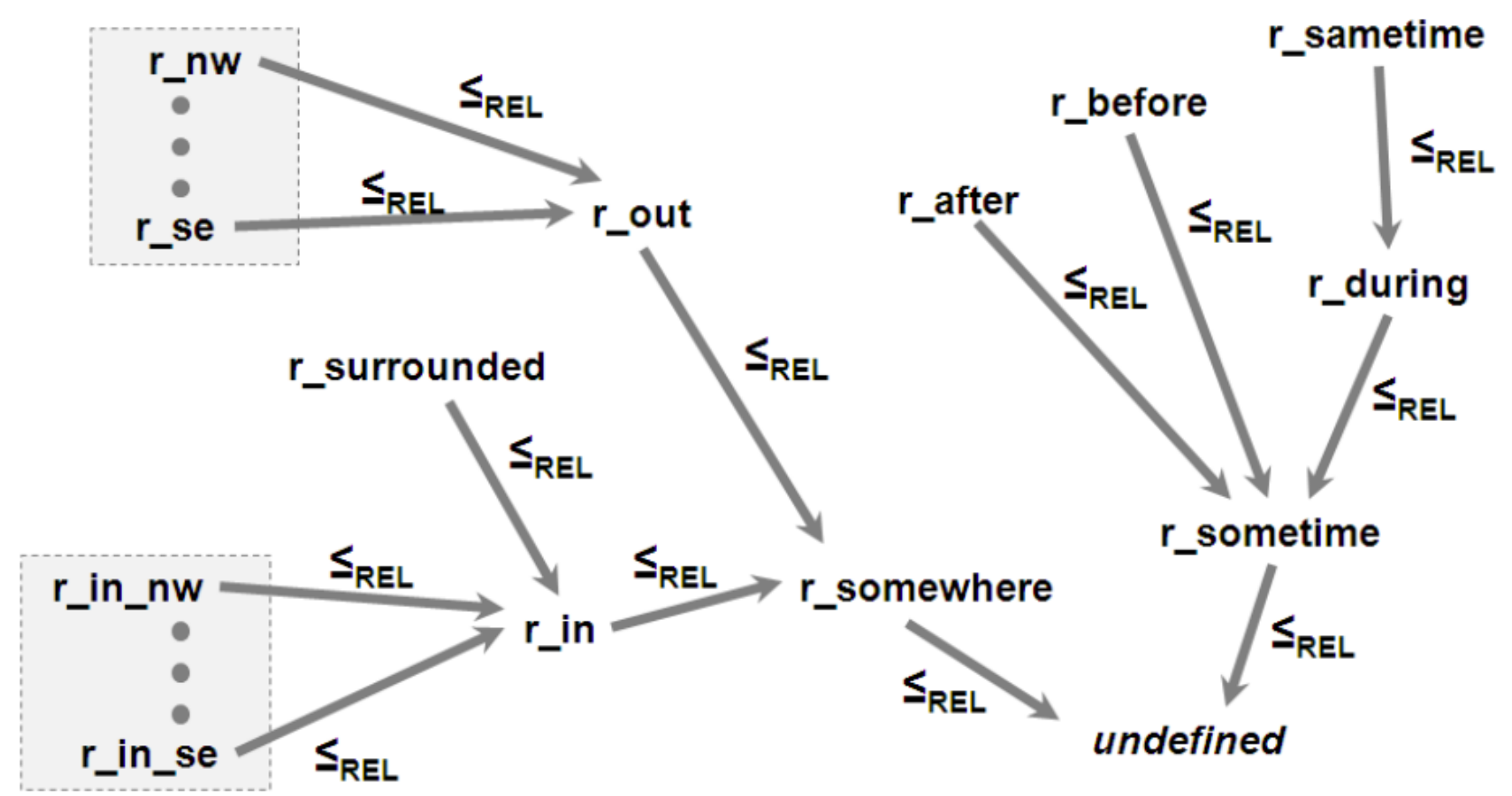

Fig. 4. The ontology of the spatio-temporal concepts 
have been performed. Tab. 1 presents a summary of characteristics for these experiments (being a core part of the beta testing of the system prototype).

The XCDC-\% value shows the relevance of the XCDC model as well as the applicability of the intelligent-bypassbased solutions; it also justifies the selection of 25 spatiotemporal primitives listed in Annex 4. High values of XCDC$\%$ confirm the relevance of the research techniques we have used to build the spatio-temporal ontology, including:

1. corpus analysis,

2. comparative analysis of well-documented and widelyknown spatial and temporal representation models ( [23]),

3. questionnaire internet-based experiments (over 2500 participants) ([21, 24]).

The SYS-\% result is affected by various syntactic phenomena ${ }^{13}$ related to the specific nature of SMS-based communication (phenomena not yet covered by the parser at the current state of the system implementation).

The global figures are also worth considering: the overall number of the text messages is 986 while the number of messages with spatio-temporal relations is 513 . That means that $52 \%$ of all messages refer to some spatio-temporal relations. What follows is the importance of spatio-temporal analysis when processing messages about critical or emergency situations.

As a final result, a content-independent reasoning module was created and later integrated with the POLINT-112-SMS $\operatorname{architecture}^{14}$.

Based on the implemented reasoning mechanisms the system answers questions about the relations that were not directly provided by informers before. Suppose the objects considered are buildings. Based on the information that building A is north-west with respect to building B and that building B is north of building $\mathrm{C}$, the system infers that building $\mathrm{A}$ is to the north-west of building $\mathrm{C}$ although none of the informers of the system has provided that information directly. It is also important to emphasize that the conclusions are not stored in the database but are generated on request for the current state of the knowledge base. Such a solution guarantees the answers to be always up-to-date in a dynamic environment and during rapid situation changes. The reasoning mechanism is based on the algorithm originally described in [25] with our further changes and extensions presented in ( [26]). Just to give a general view of the algorithm used, here is a basic example applied in the classic CDC model:

Let $R$ be a basic cardinal direction relation. Then:

Definition 1: The bounding relation of $R$, denoted by $\operatorname{Br}(R)$ is the rectangular relation with the smallest number of tiles that includes $R$.

Definition 2: $\operatorname{Most}(N, R)$ is a rectangular relation formed by the northernmost tiles of a relation $R$.
The notation $\delta\left(R_{1}, \ldots, R_{k}\right)$ is a shortcut for disjunctive relations that can be constructed by combining single-tile relations $R_{1}, \ldots, R_{k} . U_{d i r}$ is the universal cardinal direction relation.

For $R_{1}$ being a single-tile relation and $R_{2}$ - a cardinal direction relation the classic composition algorithm can be defined by the equation:

$$
R_{1} \text { о } R_{2}=R_{1} \text { o } \operatorname{Most}\left(R_{1}, \operatorname{Br}\left(R_{2}\right)\right) .
$$

Now let us consider the following example. Suppose there is information about two relations between objects X, Y, Z sent to a system as two sentences in a natural language:

$$
\begin{aligned}
& \left(\mathrm{R}_{1}\right) X \text { is to the west of } Y . \\
& \left(\mathrm{R}_{2}\right) Z \text { is to the east of } X .
\end{aligned}
$$

This is necessary if a user wants to know the location of object $\mathrm{X}$ with reference to object A (e.g. I am in Y. Where can I find $Z$ ?). According to the classic algorithm:

$R_{1} \circ R_{2}=E$ o $W=E \circ \operatorname{Most}(E, \operatorname{Br}(W))=E$ o $\operatorname{Most}(E, W)$ $=E \mathrm{o} W=\delta(W, O, E)$.

The system also answers questions about the position of a single object, as e.g. where is $X$ ? In that case, the priority analysis (within the spatio-temporal module) is activated in order to choose the best spatial reference point for the description of the object location. For example, in the soccer stadium context, the relation to the north of sector $A$ is much more precise (informative) than in the stadium, and thus the first one is used. This is so, although in general the relation to the north of (some location) covers a bigger area than in ( $a$ location), and therefore is less precise. This example shows the significance of the context analysis that is the part of the system strategy.

The POLINT-112-SMS system supports the analysis of many types of spatio-temporal relations represented in the $\mathrm{XCDC}$ model (the complete list of the relations can be found in the Annex 4). A wide variety of available relations makes the user/informer feel comfortable when describing spatiotemporal relations between objects using natural language. Based on the reasoning mechanisms as well as on context information, including knowledge about the user/informer position, the relative relations are systematically resolved i.e. converted to the corresponding absolute relations. This allows the identification of absolute spatio-temporal relations necessary for generation of the visual representation of the current situation. This means that the system functionalities are much more advanced in comparison with the basic bypass functions, as the system performs operations that (within the classic approach) are time-consuming and absorbing for the emergency center.

It is worth noticing that what provides the system with the characteristics of an intelligent information bypass is not uniquely the space-time calculus performed by the reasoning

\footnotetext{
${ }^{13}$ As e.g. anaphora which may be applied or not depending on the user's preference in the use of SMS channel in order to minimize the time of message writing/length of the message

${ }^{14}$ It may be explored as a stand-alone module in various applications
} 
module (RM). On the basis of the domain-specific information we have defined rules to infer spatiotemporal statements. An appropriate mechanism has been defined and implemented as a part of the situation analysis module (SAM). For example, the information that a person identified as ID1 has moved to sector A together with the information that ID2 is already in or is going to A, allows the inference that the two individuals are already or will soon be in the same sector. Knowing that the direct contact between ID1 and ID2 may cause riots, the system may autonomously alert the Crisis Management Center prior to the observation of any actual symptom of a real threat. The system, if necessary, initiates communication with the users in order to supply information which may be helpful in decision making. Reasoning of that kind gives the system the characteristics of an early-prevention-system as the knowledge processing is not limited to filtering and arranging the acquired knowledge but also permits to meet users' expectations that are prior to any explicit request.

\section{FUTURE WORKS, VISION AND CONCLUDING REMARKS}

It is worth noting that the solutions presented above are easily adaptable to other contexts, especially those relevant to public security and information-based decision making in critical situations. In what follows we present some potential application fields. ${ }^{15}$

Antiterrorist information gathering and prevention. The solutions implemented in our intelligent information bypass project may be reused in a system dedicated to collecting and processing antiterrorist information acquired from various sources and at different times. It is easy to imagine a situation where a seemingly low value or routine piece of information (e.g. the fact that the observed individual stopped visiting the neighboring bar) may appear meaningful in the context of the behavior of other persons or some events in the area at the same time. As in the context proper to POLINT112-SMS, the system will try to detect potential threats on the basis of memorized threat patterns, static knowledge and observations reported to the system.

Improvement of the city traffic conditions and person relocations at rush hours. Here the users will be among inhabitants of big cities, in particular users of public transportation or those using their own vehicles. The system will collect user information about current traffic jams, delays, accidents and other traffic relevant events. The system will transfer the processing results to the subscribers having activated the "advice request" function. For example, if a user signals an intention to move from A to B, than it is the system's task to provide information about all important factors in conformance with the information request, the user's profile (a priori known to the system) and the current traffic situation. Although the functionality of finding the best way from A to B is offered in many applications (as e.g. "Google maps" or popular travel organizers), the applied search algorithms typically process a well-defined static set of data with a very limited interaction with the user (if any). Adapting the information bypass solutions of the POLINT-112-SMS system will enhance real-time processing of a huge amount of data typical of the traffic in big agglomerations.

Patient monitoring after high-risk medical treatments. Shortly after hard medical treatments patients are monitored day and night by instruments, qualified personnel and (occasionally) third persons. The system may register on-line the composite data stream generated by the instruments and process it, yet without replacing the staff which is solely responsible for the patient (monitoring alerts or online pre-diagnosis hypothesis). A possible information gap may occur, e.g. when the personnel on duty is responsible for more than one patient at the same time. Besides protection against accidental loss of critical information, the data collected and processed by the system will constitute the complete documentation of the post-operation observation, useful for building the further treatment models ${ }^{16}$.

Rescue operations in natural disaster situations. Sudden weather phenomena ${ }^{17}$ that may turn into disasters concerning a huge number of people (tornados, hurricanes, forest fire, floods, mudslides) are often hardly foreseeable. These phenomena are usually very dynamic, which leads to the information chaos and makes on-line monitoring of the events difficult. Typically, the real scale of destructions may be estimated only after the event, which makes the correct management of the rescue actions difficult. The functions of intelligent bypasses similar to those of the POLINT-112-SMS will help rescue services and the concerned population to create and on-line update the map of the situation, limit information bottlenecks and chaos and reduce uncontrolled proliferation of false or contradictory information which might otherwise result in fatal decisions on the side of both the rescue forces and the population concerned.

TEDx Red Cross representative Paul Conneally presentation summary about SMS-based technologies in disaster management

The potential efficiency of SMS-based technologies in humanitarian actions in huge scale natural disasters was demonstrated at the conference (November 2011) given by Paul Conneally, the Public Communications Manager for the International Federation of the Red Cross and Red Crescent Societies responsible for application of digital technologies

\footnotetext{
${ }^{15}$ When considering other potentially important application areas for information-bypass based technology, it appears evident that in many cases application of vocal input/output may be of major interest. For a number of languages the necessary voice processing high quality technology does already exist and, if necessary, may replace or complement the text-only input

${ }^{16}$ This issue has been consulted with Dr. Wojciech Mrówczyński, professor of cardiac surgery at the Medical University in Poznań

${ }^{17}$ Similarly in case of other natural disasters as well in technological catastrophes
} 
for humanitarian aid. Convincing examples of the massive spontaneous usage of SMS technology during and after the Haiti earthquake of January 12, 2010 are presented and discussed by Conneally ( [27]). The talk "How mobile phones power disaster relief" was distributed by the TEDx organization.

From the introduction to the Conneally talk: "The disastrous earthquake in Haiti taught humanitarian groups an unexpected lesson: the power of mobile devices to coordinate, inform, and guide relief efforts. At TEDxRC2, Paul Conneally shows extraordinary examples of social media and other new technologies becoming central to humanitarian aid. Paul Conneally (the speaker) is the public communications manager for the International Federation of the Red Cross and Red Crescent Societies, and a leader in using digital technologies for humanitarian aid." (Conneall, 2011).

Conneally presents four examples, all describing simple applications within the SMS communication channel. That shows the significance of this medium. It is also important to highlight that none of these examples uses AI-processing. It means that successful application of the intelligent bypass solution could contribute considerable quality improvements in that area.

Examples mentioned:

1. Massive mobile communication during after the disastrous earthquake in Haiti, especially text messages - asks for help, data sharing, support offers, people search. Example text message: "We are in the street Saint Martin below bell air near the hotel (...) please bring us help". The humanitarian groups decided to cooperate with the telecom provider to ensure more effective and easy-to-use two-direction communication together with the ability to target specific geographic communities. The solution was quickly used by a significant number of people $(6 \mathrm{mln}$ text messages sent within 7 days). The same system have been used for:

(a) Hurricane Thomas early warnings,

(b) Public health campaigns (e.g. to prevent cholera),

(c) Violence hotlines.

The system is recognized as a huge success: $74 \%$ of the targeted population received the message, $96 \%$ found it useful, $83 \%$ took actions. That shows the potential of similar applications and the solutions proposed in this paper.

2. Using modern technology by communities in developing countries. An example is Kibera, the largest slum in Africa (located in Nairobi). Its young dwellers using basic GPS tools and SMS channel have created an interactive map of this area (including information about social events, health points, warnings against e.g. robbery and many more) free available on-line.

3. In Mongolia the SMS-based system is used for social support.

4. In Nigeria open-source SMS-based tools are used by the Red Cross to collect information from local communities (e.g. in order to prevent malaria).

\section{CONCLUDING REMARKS}

Our aim consisted in presenting a new technique of critical situation management in a class of situations where the risk of fatal information jam is high. This technique exploits advances in artificial intelligence and natural language engineering. These two disciplines are in constant and rapid growth, with the restriction that concerning the language engineering the speed of growth differs from language to language.

Our experiments with the prototype of POLINT-112-SMS do not present any computational complexity-related issues. The applied algorithms have good computational properties permitting real time processing. This concerns in particular the NL processing modules. The usage of heuristic parsing exploring the idea of pre-analysis was proposed already in early versions of POLINT systems ( $[17,28])$. In case of availability of good heuristic (as this is the case e.g. for Polish), the heuristic parsing offers average linear time complexity (cf also [29]).

Our research and development was done for Polish that belongs to the group of well-described languages for which we have NLP tools and digital language resources. These tools and resources make it feasible to create intelligent systems having language competence that may satisfy requirements such as those presented above. We hope that the results presented in this paper may be helpful as a reference for developers of similar kinds of systems (cf. above in this section) and also for languages still at the stage of developing basic resources and language engineering tools.

\section{ETHICAL ISSUES}

For several years AI experts and a large part of the public opinion have deliberated on the potential risks and threats of new advances in AI-based technologies, up to the extreme claims that (in the future) machine brains may surpass human brains in general intelligence, and consistently may replace human domination on Earth ( [30]). Russel and Norvig approached this problem already in the chapter "What if AI does succeed?" in ( [31]) and concluded that for several reasons one "cannot divorce AI research from its ethical consequences". The intended usage of AI technologies (including emulated language competence) to design and implement the information bypass as presented in this paper is apparently different from that used to produce humanoid intelligent war machines ( [32]), autonomous rescue robots ( [33]), or virtual reality environments ( [34]). The algorithms we propose are harmless, i.e. are not developed with an intention to serve 
aggressive decision making. On the contrary, the bypass algorithms described in this paper provide early prevention, e.g. in case of aggressive crowd behavior or to limit the impact of natural disasters. However, because of the wide range of potential adaptations of the intelligent bypass concept presented here, we strongly recommend considering ethical consequences of such adaptations as suggested in ( [31]).

\section{Acknowledgments}

Design and implementation of the first prototype of the system POLINT-112-SMS have been covered by the
Polish Ministry of Research and Higher Education (grant MNiSzW/R00 028 02). We wish to thank over 30 persons involved in the project (university researchers and students) who contributed in various ways by bringing to the project their know-how, experience and enthusiasm (in particular all contributors to the report ( [1])), as well as over 2,500 volunteer participants of internet-based experiments. We thank the Polish Platform for Homeland Security (PPBW) for providing their experts, officers of the Polish National Police Headquarters for various designing and end-user-testing tasks. Particular thanks go to Dafydd Gibbon and Gerard Ligozat for their precious comments at various stages of the research and for critical reading of the manuscript.

Annex 1. The Ferguson episode of August 9, 2014.

Recorded communication messages (samples) (after ( [18])):
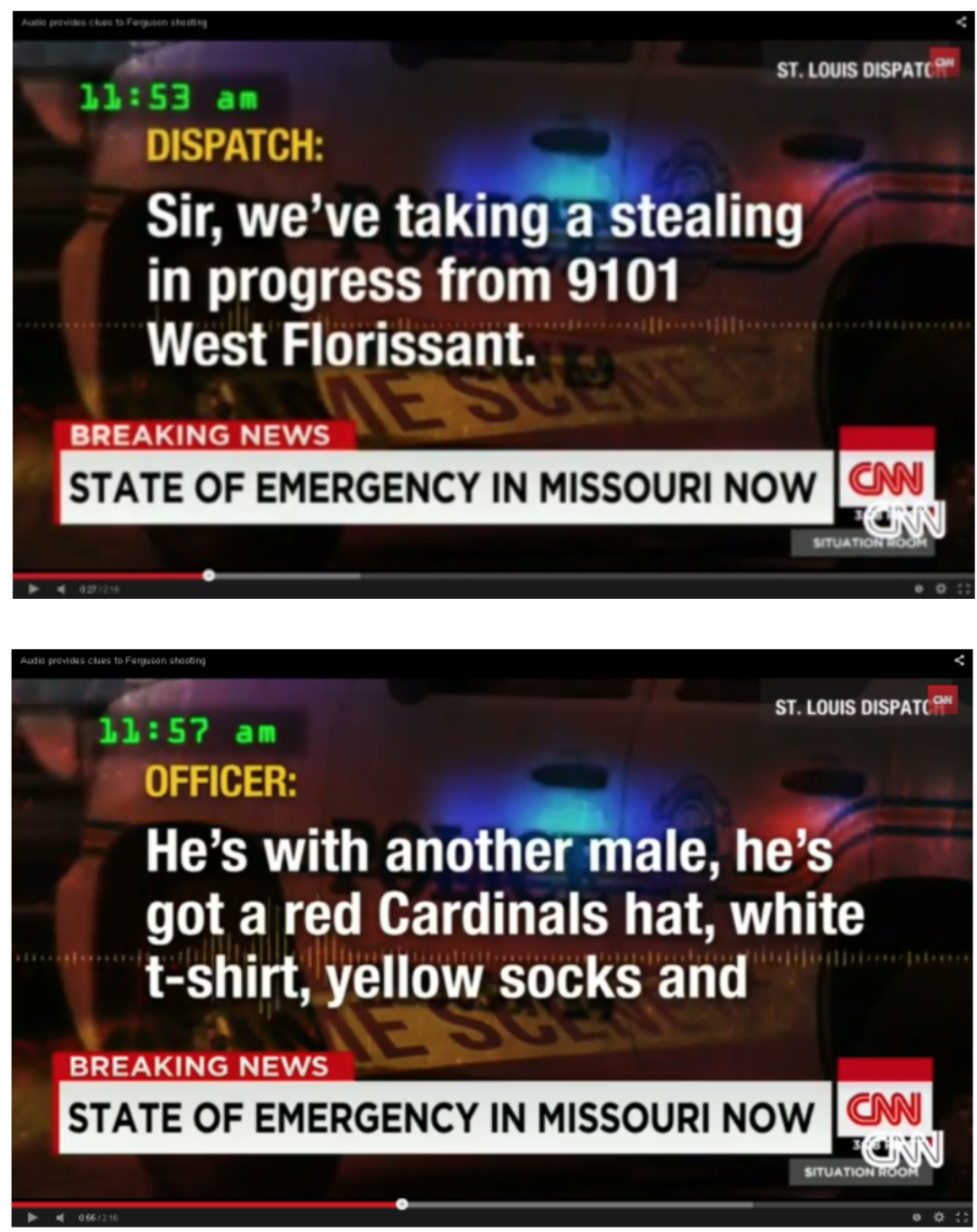

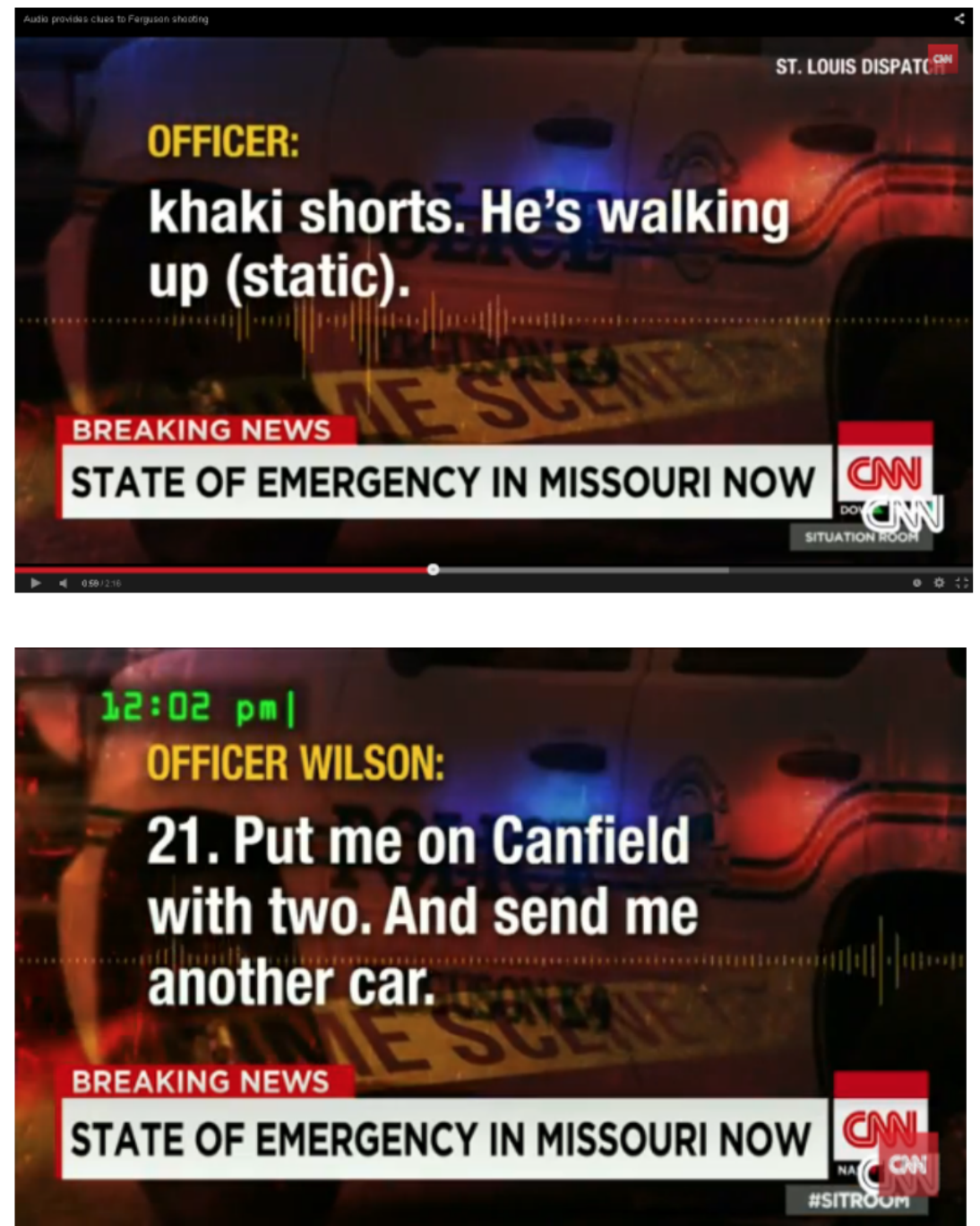

$12: 07 \mathrm{pm}$

ST. LOUIS DISPATCH

OFFICER 25:

Get us several more units over here. There's gonna be

a problem.

BREAKING NEWS

\section{STATE OF EMERGENCY IN MISSOURI NOW}

Original text of messages with Polish translations:

- dispatch: "Sir, we've taking a stealing in progress from 9101 West Florissant" / "00, mamy tu kradzież na gorąco przy West Florissant 9101" /"00" corresponds to "Sir" in the language register of Polish police patrol on duty/ 
- officer: "He's with another male, he's got a red Cardinals hat, white t-shirt, yellow socks and khaki shorts. He's walking up (static)." /"Sprawca jest z innym mężczyzną. Ma na głowie czerwony kardynalski kapelusz, biały t-shirt, żółte skarpetki i szorty khaki. Właśnie rusza./.

- officer Wilson: "21. Put me on Canfield with two. And send me another car." /"21. umieść mnie na Canfield z dwójką. I wyślij mi jeszcze jeden wózek wsparcia.C."/

- officer 25: "Get us several more units over here. There's gonna be a problem."

The Polish translations were done by an experienced Polish police officer (col. Jakub Gorczyński) instructed to reproduce the translation style and register typical of the professional security staff. They appear to be fully covered by the language competence of the POLINT-112-SMS system.

\section{Annex 2. Polint-112-SMS implementation resources}

Below we present the list of language resources used while developing POLINT-112-SMS in order to illustrate the technology requirements concerning the initial language resources that are useful to develop user-friendly systems with language competence.

\section{1. External resources (publicly available):}

1. The POLEX Polish Lexicon (ISLRN 147-211-031-223-4) is a morphological dictionary of the Polish language. It comprises about 100,000 entries. The POLEX dictionary includes the core Polish vocabulary of general interest. It is based on a precise machine-interpretable formalism (coding system), the same for all categories (classes of speech) ( [35]). The dictionary entries are of the following form:

\section{BASIC_FORM+LIST_OF_STEMS+PARADIGMATIC_CODE+DISTRIBUTION_OF_STEMS}

The paradigmatic code (= inflection code) contains full paradigmatic information, in particular all inflection endings are encoded in an unambiguous way.

The resource contains:

- more than 42,000 nouns,

- more than 12,000 verbs,

- more than 15,000 adjectives,

- more than 25,000 participles,

- about 200 pronouns.

The resource creator is Zygmunt Vetulani. POLEX is distributed now by ELRA (Vetulani 2016).

2. IPI PAN Corpus contains some 1.5 billion text words and is known as the National Corpus of Polish (NKJP) ( [36]).

3. Universal Dictionary of Polish (UDJP, Uniwersalny Słownik Języka Polskiego) features 100,000 entities ( [37])

4. Internet dictionary SJP.PL contains some 180,000 entries composed of lemmas with derived forms.

5. Generative Dictionary of Polish Verbs (Generatywny Słownik Czasowników Polskich) describes the Polish verb valency ([38]). This lexicon characterizes the syntactic and semantic connectivity of over 10,000 verbs.

\section{2. Internal resources:}

\section{Corpora}

(a) Printed texts (electronic source) - This small corpus (some 1,000,000 tokens) permitted acquisition of terminology rarely observed or absent in general corpora (IPI PAN), especially in the area of operational police activity and terrorism ( [39-41]). 
(b) SMS dialogue corpora - a corpus of some 1,700 text messages composed of 1,843 sentences (24,599 words). This corpus was very useful at the system implementation stage, as it permitted us to discover various new phenomena, important for correct functioning of beta prototypes ( [12])). The method for building the corpus was inspired by ([42]).

(c) SMS experimental corpora contained 1,374 sentences.

(d) Speech corpora - access to 23,469 recorded telephone connections registered (recorded dialogues from the "997 Polish public emergency service") (unpublished).

2. Dictionaries

(a) Extensions to the electronic morphological dictionary POLEX.

(b) The dictionary of verb-noun collocations - over 20,000 verb-noun collocations (Vetulani G. 2000 and 2012 ).

3. PolNet - Polish Wordnet (lexical ontology) - The first stage of building PolNet ended with the resource amounting to some 11,700 synsets for over 20,300 word-senses (and 12,000 nouns). Then this basic resource was extended with verb part which was composed of over 1,500 synsets corresponding to some 2,900 word+meaning pairs for 900 most important Polish simple verbs (Vetulani 2014). (PolNet 3.0 is now available cf. ISLRN 944-121-942-407-9).

\section{Annex 3. System-user dialogues. Examples.}

The examples presented below were generated at the prototype testing phase.

\section{Example 1.}

Informer: Kowal nosi bluzę i czarne spodnie. Kowal i Wolski są na murawie. Kowal i Wolski należą do bojówki.

(Kowal is wearing a blouse and black trousers. Kowal and Wolski are on the football field. Kowal and Wolski are members of a hooligan squad) System: 'Zrozumiałem' (Understood)

Informer: Osoba, która nosi czarne spodnie, jest niebezpieczna. Kowal i Wolski atakują policjantów kamieniami.

(The person who wears black trousers is dangerous. Kowal and Wolski are attacking policemen with stones)

System: 'Zrozumiałem' (Understood)

Analyst: Kto atakuje policjantów? (Who is attacking the policemen?)

System: 'Kowal. Wolski. Brak dalszych odpowiedzi!' (Kowal. Wolski. No more answers!)

Analyst: Kto jest niebezpieczny? (Who is dangerous?)

System: 'Kowal. Wolski. Brak dalszych odpowiedzi!' (Kowal. Wolski. No more answers!)

Analyst: Czy istnieje niebezpieczna osoba, która nie została złapana?

(Is there a dangerous person who has not been captured?)

System: 'Tak, kilka, w szczególności istnieje: Kowal !' (Yes, a few persons, in particular Kowal!)

Informer: Kowal ucieka. (Kowal is running away)

System: 'Zrozumiałem' (Understood)

Informer: Kowal został złapany. (Kowal has been captured) 


\section{Example 2.}

Anaphora reference identification: the system recognizes two people as a group and is able to find the correct references within informer's messages. Please also note there are two different informers engaged - the system correctly distinguishes them and communicates with each of them independently (while at the same time collects and process the arriving information as a whole).

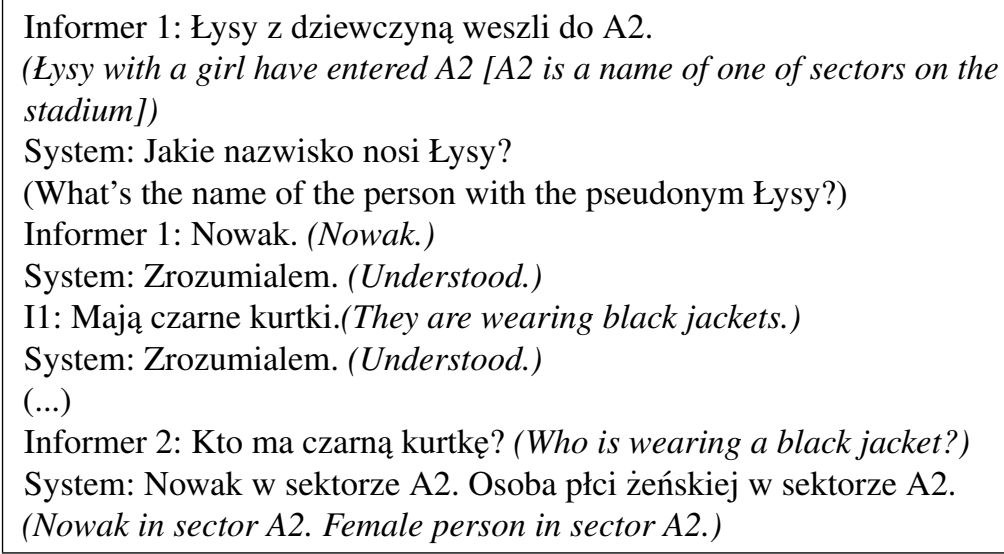

Example 3. (3 users involved)

Informer 1: Kowal z Wolskim i Olem spotkali się w sektorze A1.

System (to Informer 1): Jakie nazwisko nosi osoba o pseudonimie Olo, która uczestniczyła w następującym zdarzeniu: zdarzenie typu spotkanie, lokalizacja przestrzenna: sektor a1, uczestnicy czynności: osoba o pseudonimie Olo, Jan Wola o pseudonimie Wolski, Kowalski o pseudonimie Kowal?

(What is the name of the person with the alias Olo, who participates in the following event: meeting, localization: sector Al, performers: person with the alias Olo, Jan Wola with the alias Wolski, Kowalski with the alias Kowal?)

Informer: Olo nazywa się Jan Olak. (Olo's name is Olak.)

System: Zrozumiałem. (Understood.)

Informer 2: Kto spotkał się w sektorze A1? (Who met in sector A1?) System: Zdarzenie typu spotkanie, wykonawcy czynności: kibic Jan Olak o ksywie Olo, kibic Jan Wola o pseudonimie Wolski, kibic Kowalski o pseudonimie Kowal.

(meeting, localization: sector al, performers: Jan Olak with the alias Olo, Jan Wola with the alias Wolski, Kowalski with the alias Kowal)

Informer 2: Gdzie jest Kowal? (where is Kowal?)

System: Kibic Kowalski o pseudonimie Kowal, lokalizacja : w miejscu sektor A1 z kibicami drużyny „Lech Poznań” w odległości zero.

(team supporter Kowalski with the alias Kowal, localization: sector Al with the supporters of Lech Poznan, at distance zero)

Informer 1: Kowal przeszedł do sektora A2. (Kowal moved to sector A2.)Informer 3: Kto uczestniczy w spotkaniu w A1? (Who takes part in the meeting in sector Al?)

System (to Informer 3): Zdarzenie typu spotkanie, wykonawcy czynności: kibic Jan Olak o pseudonimie Olo, kibic Jan Wola o pseudonimie Wolski.

(Meeting, soccer fans: Jan Olak alias Olo, Jan Wola alias Wolski.) 


\section{Annex 4. Spatio-temporal relations.}

The external direction relations which refer to the 8 basic geographical directions describe the mutual spatial configuration of two disconnected objects.

r_nw (e.g. $B$ is to the north-west of $A)$,

r_n (e.g. $B$ is to the north of $A$ ),

r_ne (e.g. $B$ is to the north-east of $A)$,

r_w (e.g. $B$ is to the west of $A$ ),

r_e (e.g. $B$ is to the east of $A$ ),

r_sw (e.g. $B$ is to the south-west of $A$ ),

r_s (e.g. $B$ is to the south of $A)$,

r_se (e.g. $B$ is to the south-east of $A$ ),

Internal direction relations which describe a situation where a target object is located inside a reference one.

r_in_nw (e.g. $B$ is in the north-west of $A$ ),

r_in_n (e.g. $B$ in the north of $A)$,

r_in_ne (e.g. $B$ in the north-east of $A$ ),

r_in_w (e.g. $B$ in the west of $A$ ),

r_in_e (e.g. $B$ is in the east of $A$ ),

r_in_sw (e.g. $B$ is to the south-west of $A$ ),

r_in_s (e.g. $B$ is to south of $A$ ),

r_in_se (e.g. $B$ is in the south-east of $A$ ),

Topological relations that make abstraction from the cardinal direction; we use them in everyday language when the cardinal direction is unknown or the particular relationship concerns all the directions.

r_in (e.g. $B$ is inside $A$ ),

r_out (e.g $B$ is outside of $A$ ),

r_surrounded (e.g. $B$ is surrounded by $A$ ),

r_somewhere (e.g. $B$ is somewhere in the region of $A$ ),

Temporal relations.

r_before (e.g. $B$ is before $A$ ),

r_after (e.g. $B$ is after $A$ ),

r_sametime (e.g. $B$ is at the same time as $A$ ),

r_during (e.g. $B$ is during $A$ ),

r_sometime (e.g. $B$ is sometime around $A$ ).

Consideration of additional quantitative topological relations as close, far, between may also appear useful (Osiński, 2013).

\section{References}

[1] Z. Vetulani, J. Marcinak, T. Obrębski, G. Vetulani, A. Dąbrowski, M. Kubis, J. Osiński, J. Walkowska, P. Kubacki, $\mathrm{K}$. Witalewski, Language resources and text processing technologies. POLINT-112-SMS as example of homeland security oriented application (in Polish), ISBN 978-83-2322155-5, ISSN 1896-379X, Adam Mickiewicz University Press, Poznań, 2010.

[2] Z. Vetulani, J. Marciniak, Natural Language Based Communication between Human Users and the Emergency Center: POLINT-112-SMS, in: Human Language Technology. Challenges for Computer Science and Linguistics. LTC 2009. Revised Selected Papers, Z. Vetulani, Ed. (Springer Verlag Berlin-Heidelberg) 6562 of LNAI, pp. 303-314, 2011.

[3] A.B. Gjurrv, "Gjurrv Report" (full Norwegian text at the Government of Norway website, August 2012). (https://www.regjeringen.no/no/dokumenter/nou-201214/id697260/), 2012.

[4] NATO (2012): Norway-NATO (The Norwegian Delegation to NATO), "22 July Commission's report", 14.08.2012, http://www.norway-nato.org/eng/News/22-
July-Commissions-report/ [the easiest access to this source is by Internet].

[5] BBC (2012): News Europe, "Norway police «could have stopped Breivik sooner»", 13.08.2012, http://www.bbc.com/news/world-europe-19241327 [the easiest access to this source is by Internet].

[6] Reuters (2012): "Norway could have prevented Breivik massacre, says commission", 13.08.2012, (http://www.reuters.com/article/2012/08/13/us-breivikcommission-idUSBRE87C0PE20120813).

[7] Guardian (2012): The Guardian, "Anders Behring Breivik could have been halted - report", 13.08.2012, http://www.theguardian.com/world/2012/aug/13/andersbehring-breivik-attacks-halted-report [the easiest access to this source is by Internet].

[8] J.D Haller, A.S. Olearchyk, Cardiology's 10 Greatest Discoveries, Tex Heart Institute Journal 29(4), 342-344 (2002).

[9] Z. Vetulani, PolNet-Polish WordNet, in: Z. Vetulani, Z. and J. Mariani, (Eds.): Human Language Technology Challenges for Computer Science and Linguistics. LTC 2011. Revised Selected Papers. vol. 8387 of LNAI, SpringerVerlag Berlin Heidelberg, pp. 408-416, 2014. 
[10] M. Kubis, A query language for a wordnet-like lexical database, $\mathrm{PhD}$ dissertation (thesis) (in Polish with English abstract), Poznań, Adam Mickiewicz University, 2013.

[11] J. Osiński, Spatio-Temporal Knowledge Modeling and Processing. The XCDC Model - Theoretical Aspects and Applications, $\mathrm{PhD}$ dissertation (thesis) (in Polish with English abstract), Poznań, Adam Mickiewicz University, 2012.

[12] J. Walkowska, Modelowanie kompetencji dialogowej człowieka na potrzeby jej emulacji $w$ zarzadzajqcych wiedzq systemach informatycznych wspótpracujacych $z$ wieloma uzytkownikami. PhD dissertation (thesis) (in Polish with English abstract). Warsaw University, 2012.

[13] Z. Vetulani, Language Resources in a Public Security Application with Text Understanding Competence. A Case Study: POLINT-112-SMS, Proceedings of the LRPS Workshop at LREC 2012, May 27, 2012. Istanbul, Turkey, ELRA: Paris, pp. 54-63, ISBN 978-2-9517408-7-7, 2012.

[14] J.F Kelley, An empirical methodology for writing userfriendly natural language computer applications, in: Proceedings of ACM SIG-CHI '83 Human Factors in Computing systems (Boston, 12-15 December 1983) Smith R. N., R., Pew, W., Janda, A.0 (Eds.) (New York, ACM), 193-196, 1983.

[15] D. Gibbon, I. Mertins, R.K. Moore (Eds.), Handbook of Multimodal and Spoken Dialogue Systems: Resources, Terminology and Product Evaluation. Dordrecht: Kluwer, 2000.

[16] P. Prat M. Aulinas, C. Turon, J. Comas, M. Poch, Role playing games: a methodology to acquire knowledge for integrated wastewater infrastructures management in a river basin scale. Water Sci. Technol. 59(9), 1809-1816 (2009).

[17] Z. Vetulani, J. Marciniak, Corpus Based Methodology in the Study and Design of Systems with Emulated Linguistic Competence, in: Natural Language Processing NLP 2000, D. Christodoulakis, Ed. (Springer Verlag BerlinHeidelberg) vol. 1835 of Lecture Notes in Artificial Intelligence, pp. 346-357, 2000.

[18] CNN (2004): State of Emergency in Missouri Now (2004): the easiest access to this source is by Internet on https://www.youtube.com/results?search_query $=$ State + of + Emergency+in+Missouri+Now+; last access on May 3, 2016.

[19] R.K. Goyal, M.J. Egenhofer, Cardinal directions between extended spatial objects, in: IEEE Transactions on Knowledge and Data Engineering, 2001.

[20] G. Ligozat, Z. Vetulani, J. Osiński, Spatiotemporal Aspects of the Monitoring of Complex Events for Public Security Purposes, Spatial Cognition and Computation: An Interdisciplinary Journal 11(1), 103-128 (2011).

[21] J. Osiński, Acquisition of Spatial Relations from an Experimental Corpus, in Human Language Technology. Challenges for Computer Science and Linguistics, 4th Language and Technology Conference, Poznan, Poland, November 6-8, 2009, Revised Selected Papers, Z. Vetulani (Ed.) vol. 6562 of (Springer) Lecture Notes in Artificial Intelligence, pp. 388-399, 2011.

[22] J. Osiński, The XCDC Relations as a Spatio-Temporal Ontology, in Human Language Technology Challenges for Computer Science and Linguistics, 5th Language and Technology Conference, LTC 2011, Poznan, Poland, November 25-27, 2011, Revised Selected Papers, Z. Vetulani, J. Mariani Eds. (Springer Verlag Berlin-Heidelberg) vol. 8387 of Lecture Notes in Artificial Intelligence, pp. 104-115, 2014.
[23] J. Osiński, Extended CDC vs Other Formalisms - The Comperative Analysis of the Models for Spatio-temporal Reasoning, in Artificial Intelligence and Soft Computing, 11th International Conference, ICAISC 2012, Zakopane, Poland, April 29 - May 3, 2012, Proceedings, Part II, Rutkowski, L., M. Korytkowski, R. Scherer, R. Tadeusiewicz, L. Zadeh, J. Zurada (Eds.) vol. 7268 of (Springer) Lecture Notes in Artificial Intelligence, pp. 679687, 2012.

[24] J. Osiński The Construction of the Relative Distance Fuzzy Values Based on the Questionnaire Experiment, in AI*IA 2013: Advances in Artificial Intelligence, XIIIth International Conference of the Italian Association for Artificial Intelligence, Turin, Italy, December 4-6, 2013, Proceedings, M. Baldoni, M. C. Baroglio R. Boella G., Micalizio (Eds.), Springer Verlag Berlin-Heidelberg, vol. 8249 of Lecture Notes in Artificial Intelligence, pp. 217-226, 2013.

[25] S. Skiadopoulos, M. Koubarakis, Composing cardinal direction relations. in: Proceedings of Seventh International Symposium on Spatial and Temporal Databases. Lecture Notes in Computer Science, vol. 2121, Springer, pp 299317, 2001.

[26] K. Osiński, Using Extended Cardinal Direction Calculus in Natural Language based Systems, in Artificial Intelligence and Soft Computing, 10th International Conference, ICAISC 2010, Zakopane, Poland, June 13-17, 2010, Part II, L. Rutkowski, R.R. Scherer L. Tadeusiewicz J. Zadeh Zurada, Eds., vol. 6114 of. Lecture Notes in Artificial Intelligence, (Springer Verlag Berlin Heidelberg) pp. 606-613, 2010.

[27] P. Conneally, Digital humanitarianism (talk published by TEDx in form of video). Accessible at https://www.ted.com/talks/paul_conneally_digital_humanitarianism (last access on May 3, 2016), 2011.

[28] Z. Vetulani, Lexical preanalysis in a DCG parser of Polish, in: Betriebslinguistik und Linguistikbetrieb. Akten des 24 Linguistischen Kolloquiuums, Bremen 1989 (Linguistische Arbeiten 260/261), Tübingen: Niemeyer, 341-350, 1991.

[29] Ch.R. Huyck, S.L. Lytinen, : Efficient Heuristic Natural Language Parsing, AAAI-93 P50ceedings. AAAI, 1993.

[30] N. Bostrom : "Superintelligence: Paths, Dangers, Strategies", Oxford University Press, 2014.

[31] S. Russel, P. Norvig, Artificial Intelligence. A Modern Approach (second edition), Prentice Hall, Pearson Education, Inc., 2002.

[32] S. Musk, S. Wozniak, D. Hassabis, S. Hawking, : Autonomous Weapons: an Open Letter from AI \& Robotics Researchers, IJCAI, July 28, 2015, Future of Life Institute [the easiest access to this source is by http://futureoflife.org/AI/open_letter_autonomous_weapons; access August 05, 2015], 2015.

[33] N. Rossini, A. Esposito, Modeling Human Behaviour in Emergency: A Research Agenda for the Creation of a Rescue Robot, in Frontiers in Artificial Intelligence and Applications, B. Apolloni, S. Bassis, A. Esposito, C.F. Morabito Eds. (IOS Press), pp. 235-246, 2011.

[34] A. Shendarkar, K. Vasudevan, S. Lee, Young-Jun Son, Crowd simulation for emergency response using BDI agent based on virtual reality, Simulation Modelling Practice and Theory 16(9), 1415-1429 (2008)

[35] Z. Vetulani, B. Walczak, T. Obrębski, G. Vetulani : Unambiguous coding of the inflection of Polish nouns and its application in the electronic dictionaries - format POLEX, Adam Mickiewicz University Press, Poznań, 1998. 
[36] A. Przepiórkowski, M. Bańko, R.L Górski, B. Lewandowska-Tomaszczyk, B., M. Łaziński, P. Pęzik, National Corpus of Polish. in: Proceedings of the 5th Language \& Technology Conference: Human Language Technologies as a Challenge for Computer Science and Linguistics, ,pp. 259-263, Poznań, 2011.

[37] D. Dubisz (Ed.), Uniwersalny stownik jezyka polskiego $P W N$, (Universal dictionary of Polish, in Polish), 2nd edition, Warszawa: Wydawnictwo Naukowe PWN, 2006.

[38] K. Polański, Polański, (Ed.) (1980-1992): Stownik syntaktyczno-generatywny czasowników polskich (Generative Dictionary of Polish Verbs) (in Polish), t. I-IV, Os- solineum, Wrocław, 1980-1990, t. V, Instytut Języka Polskiego PAN, Kraków, 1992.

[39] Zb. Rau,: Przestępczość zorganizowana w Polsce i jej zwalczanie (M.A. dissertation, in Polish)), Wyd. Zakamycze, Kraków, 2002.

[40] W. Filipkowski, Zwalczanie przestęczości zorganizowanej $w$ aspekcie finansowym, Grupa Wolters Kluwer, Kraków, 2004.

[41] H. Januszka, S. Gembara, Elementy nowoczesnego zarzadzania w policji, Poznań, 2005.

[42] C. Fairon, S. Paumier, A Translated Corpus of 30,000 French SMS, in: Proceedings of LREC 2006, Genova, N. Calzolari, Ed., ELRA/ELDA, Paris, 2006.



Zygmunt Vetulani (1950) is a full professor in technical computer science. He received his MSc in Mathematics and his MA in Romance Studies from the Adam Mickiewicz University in Poznań, and his PhD in the Foundation of Mathematics from the University of Warsaw. The Alexander von Humboldt Foundation fellowship at the University of Bielefeld (1987-1989). Initiator and organizer of Language and Technology Conferences since 1995. Author of over 110 research papers, 6 books, and ISLRN indexed language resources. Management of various national and international research projects. His present research interests are in computer linguistics, natural language resources, AI applications in the field of homeland security, applications of computer science methods in humanities. Married, 2 daughters. Hobby: active practice of sport. (www.amu.edu.pl/ vetulani)

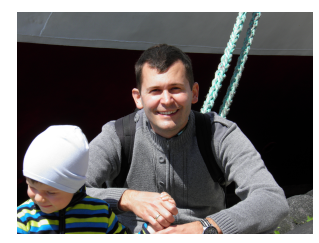

Jędrzej Osiński has a Ph.D. in artificial intelligence and strong research background in computer science. He gained experience working within Polish Platform for Homeland Security (government grant). After 8 years of academic teaching, he currently lectures about software testing and products, AI applications and IT business start-up at Adam Mickiewicz University in Pozna?. He combines his academic career with being a Senior Quality Assurance Engineer and Line Manager in Cognifide, an experience management consultancy. ISTQB Advanced Level Test Analyst and Test Manager. He is an author of 13 scientific papers and co-author of two books. During his professional and scientific career he was involved in a number of different conferences as a speaker, papers reviewer and organizer. His scientific interests are mostly focused on spatio-temporal modelling and reasoning, knowledge representation, natural language processing, qualitative calculus and fuzzy sets. He is also involved in various initiatives promoting AI, science and modern technologies e.g. blog posts, science days, invited talks and TV appearances. 